\title{
O Lutero de Lucien Febvre: uma discussão sobre biografia e história da historiografia
}

Lucien Febvre's Luther: A Discussion on Biography and History of Historiography

FEBVRE, Lucien. Martinho Lutero, um destino. São Paulo: Três Estrelas, 2012. 359 p.

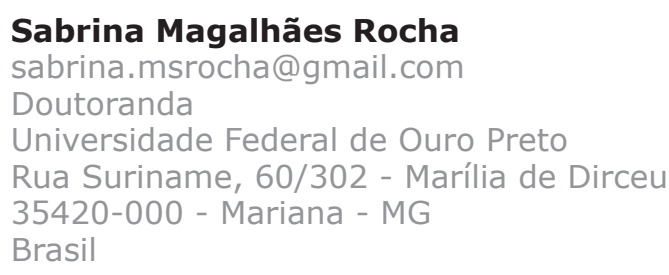

Palavras-chave

Biografia; História da historiografia; Lucien Febvre.

280 Keywords

Biography; History of historiography; Lucien Febvre. 
Martinho Lutero, um destino, obra de Lucien Febvre de 1928 e editada no Brasil pela primeira vez em 2012 pela editora Três Estrelas, não é exatamente uma novidade para a historiografia brasileira. Principalmente em razão da edição em espanhol pela Fondo de Cultura Econômica (FEBVRE 1998) e da edição portuguesa, vários historiadores brasileiros já estão familiarizados com esse texto. Isso não reduz a importância da edição em português do Brasil dessa obra que ainda hoje persiste como referência para os estudiosos da Reforma. A edição brasileira, na medida em que viabiliza o acesso a um público mais amplo, apresenta novas oportunidades de estudar a obra sob diversas perspectivas.

A relevância desta edição pode ser sentida a partir de suas primeiras recepções, nas resenhas publicadas na Revista de História da Biblioteca Nacional e no jornal Folha de São Paulo (CAMPOS 2012, p. E6; WOOLEY 2013). Essas resenhas foram produzidas por historiadores da religião, que enfatizaram as contribuições da obra para aquele campo. Já nossa análise explora uma perspectiva diferente, razão pela qual acreditamos ainda poder contribuir com mais esta resenha. Nossa leitura busca explorar a obra a partir das lentes da história da historiografia, buscando compreender sua construção metodológica, sua relevância na historiografia francesa dos anos 1920 e suas possíveis contribuições para o debate contemporâneo desse campo.

Em 1928, um ano antes da inauguração da Annales, revista que consagraria seu nome, Lucien Febvre publicou a obra Martinho Lutero, um destino. Nesse momento Febvre contava cinquenta anos e era professor na Universidade de Estrasburgo, instituição que, apesar de toda a simbologia que representava para a nação francesa no pós-guerra no sentido da reconquista cultural do leste, não conhecia a notoriedade das instituições parisienses. Não se pode dizer, contudo, que Febvre fosse um desconhecido no meio historiográfico francês, pois já gozava de notoriedade em função de algumas de suas publicações, sobretudo A terra e a evolução humana, de 1922, e pelas suas frequentes contribuições para a Revue de Synthèse, dirigida pelo teórico belga Henri Berr.

O título da obra Martinho Lutero, um destino conduz o leitor imediatamente para a compreensão de que se trata de uma análise da trajetória e de uma biografia do reformador protestante. Contudo, não é esse o rótulo que Febvre quer associar à sua obra e afirma isso já na primeira linha do prefácio: "Uma biografia de Lutero? Não. Uma opinião sobre Lutero, nada mais" (FEBVRE 2012, p. 11). Em seguida, o autor indica o que se encontraria naquela obra, demonstrando quais seriam seus objetivos:

Traçar a curva de um destino que foi simples, mas trágico; situar com precisão os poucos pontos realmente importantes por onde passou essa curva; mostrar de que maneira, sob a pressão de que circunstâncias, seu impulso inicial teve de esmorecer, e seu traçado original, inflectir-se; colocar assim, acerca de um homem de singular vitalidade, esse problema das relações entre o indivíduo e a coletividade, entre a iniciativa pessoal e a necessidade social, que é, talvez, o problema essencial da história: tal foi nosso intuito (FEBVRE 2012, p. 11). 
Essa descrição de Febvre, aos nossos olhos de leitores do século XXI, apresenta dificuldades. Como afirmar que não se trata de uma biografia se a descrição que se faz ali comporta as principais características desse gênero, sobretudo desse gênero no campo historiográfico? Por que a necessidade de afirmação peremptória de que não se encontraria ali uma biografia? A resposta a essas questões parece-nos estar no significado que o conceito biografia guardava na França das primeiras décadas do século XX, no status que esse gênero gozava na comunidade de historiadores acadêmicos.

Em resenha dedicada a analisar o livro de Febvre, publicada logo após o lançamento, Henri Berr afirmava que no cenário francês daquele momento a biografia estava na moda (em seus termos, "trop à la mode"). Ela permeava o terreno daqueles escritores alcunhados de vulgarizadores da história, descompromissados com o métier, isto é, com o trabalho com a história como um ofício científico. As biografias disponíveis naquele momento, nos termos de Henri Berr, seriam romanceadas, desprovidas de objetividade. E exatamente por esse motivo o texto de Lucien Febvre, fruto de efetiva operação historiográfica, ${ }^{1}$ não poderia receber a alcunha de biografia. Pelas mãos de Berr, a solução para o impasse de como designar essa obra estaria numa formulação do tipo "biografia psicológica". Esse tipo biográfico se distinguiria dos demais por não ser romanceado, mesmo possuindo narrativa rica e atrativa no aspecto literário, e por estar assentado em vasto e seguro saber (BERR 1929, p. 10).

A interpretação de Lucien Febvre sobre Lutero foi recebida como singular 282 por se propor a estudar o reformador a partir desse método que se denominou "análise psicológica", não apenas por Henri Berr. O historiador francês Henri Hauser, em resenha da obra publicada na Revue Critique d'Histoire et de Littérature, enaltece o fato de Febvre ter retomado as reconstituições psicológicas produzidas pela "escola romântica" e que, em nome da "crítica objetiva", haviam sido ridicularizadas pela historiografia. Hauser comemora ainda que Febvre tenha tido a ousadia de ser um historiador que cita Michelet e que "ressuscita as almas do passado, em suas próprias experiências morais" (HAUSER 1928, p. 500).

Esta biografia aborda especialmente o período compreendido entre 1517 e 1525, fase da vida de Lutero que evidenciaria mais nitidamente alguns traços do personagem histórico e que, segundo Febvre, ainda carecia de estudos, especialmente na academia francesa. No prefácio da segunda edição da obra, o historiador francês afirma que seu interesse em estudar a figura de Lutero era motivado pela relevância histórica da questão em razão da presença marcante do luteranismo na Alemanha e, em seus próprios termos, da relação do luteranismo com a "mentalidade" dos povos germânicos.

O intuito de Febvre era produzir uma obra sobre Lutero de caráter distinto dos muitos trabalhos disponíveis até então. É importante lembrar que desde pelo menos o século XIX havia um vasto número de textos sobre vida e obra de Lutero, tanto na esfera teológica quanto política e histórica; textos que não raramente guardavam maior aproximação com as causas que buscavam defender que propriamente com

${ }^{1}$ Empregamos aqui o sentido do conceito explorado por Michel de Certeau (2008). 
a pesquisa sistemática sobre o reformador. Quando Febvre afirma, portanto, seu desejo de produzir uma obra de caráter distinto, ele expressa sua pretensão de afastar-se desse terreno de paixões políticas e religiosas. O quanto este texto está distante dessas paixões é uma questão que não pretendemos aprofundar aqui, pois sua complexidade conduziria o raciocínio em outra direção. É certo que há envolvimento do autor, entre outros aspectos, no que se refere ao julgamento das características atribuídas aos alemães. Também se observa que, em diversos momentos, Febvre se revela seduzido pela personalidade de Lutero, pelo poder encantatório de seu idealismo sobre os alemães. No entanto, não se pode negar o esforço de Lucien Febvre por se desvincular das muitas pré-concepções e julgamentos sobre Lutero disponíveis naquele contexto. ${ }^{2}$

Essa perspectiva de distanciamento não se formou, entretanto, desconsiderando a literatura existente. Ao contrário, o texto revela, tanto nas citações da bibliografia quanto no confronto com os autores ao longo dos capítulos, o vasto estudo dessa literatura. Na bibliografia da obra destacam-se textos produzidos na Alemanha, cuja comunidade, evidentemente, era a que mais produzia sobre Lutero. São referenciadas leituras de importantes intelectuais alemães tanto do século XIX como contemporâneos de Lucien Febvre; nomes como Leopold von Ranke, Max Lenz, Adolf von Harnack, Georg von Below e Ernst Troeltsch, um teólogo a quem Febvre se referia como um "homem de grande talento".

Febvre argumenta que a Alemanha era um território de contrastes em que a riqueza econômica se contrapunha a debilidades morais e políticas. Haveria lá grande disposição para mudanças, e várias vozes já as reclamavam. É esse terreno que a partir de 1525 será um campo fértil para a disseminação do luteranismo, mas um luteranismo muito distinto daquele visado pelo próprio Lutero. A grande questão para Febvre é que, apesar de estar em um campo de efervescência de ideias políticas e sociais, Lutero não poderia ser visto como uma das vozes que clamavam por mudanças. Nota-se, então, que a interpretação febvreana promove efetivo distanciamento das interpretações que buscavam associar a Lutero o rótulo de um revolucionário, de um reformador social e político.

A tese defendida por Febvre é a de que os protestos desencadeados por Lutero não teriam origem teológica ou social, mas sim psicológica. Em sua argumentação, as teses de Lutero não seriam fruto de uma análise crítica do contexto alemão, nem de uma revolta contra as degradações institucionais da Igreja Católica. A revolução de Lutero seria pessoal, espiritual, fruto de seu fervor religioso. Suas manifestações afirmariam antes o desejo de proclamar as "descobertas" advindas de seu contato íntimo com Deus. Para Febvre, Lutero era um profeta e não um lógico, motivo pelo qual não teria feito cálculos políticos ou ponderações. É interessante lembrar que, neste ponto, Febvre busca amparo na explicação oferecida por Nietzsche de que as ações de Lutero não se guiavam apenas por processos de ordem doutrinal, mas também moral e psicológica. 
Ainda no que se refere à desconstrução da imagem de um reformador político, o historiador francês argumenta que a aproximação de Lutero com o nacionalismo alemão só se dá a partir de 1520, momento em que ele faz seu primeiro manifesto de cunho mais social. No entanto, ainda segundo Febvre, mesmo nesse momento, não é a política que move Lutero. Febvre aponta que a visão política de Lutero era curta, "pouco maquiavélica"; em seus termos, ele permanecia magnífico e ingênuo, um idealista absoluto que se colocava acima das misérias do mundo real. Sobre o papel de Lutero como um teólogo reformador da Igreja, a desconstrução febvreana passa pela afirmação de que o episódio das indulgências, entre 1515 e 1517, teve um peso pequeno na trajetória de Lutero, mas foi superestimado pela literatura. As 95 teses não seriam uma declaração de guerra, e sim uma advertência, de forma que o cisma teria sido uma iniciativa da Igreja Romana e não propriamente de Lutero.

Cabe assinalar que a metodologia empregada por Febvre na obra em apreço não consistiu apenas em traçar uma análise psicológica, mas também em demonstrar as relações entre o indivíduo e a coletividade. Parece-nos possível afirmar que essa operação aparece no texto ainda no campo da psicologia, a partir do momento em que a "análise psicológica" de Lutero é associada à afirmação dos traços que marcariam a "psicologia coletiva do povo alemão". o Lutero de Lucien Febvre é, por todos os aspectos (nas formas de pensar, sentir e agir), definido como um alemão, um homem plenamente inserido em sua "raça", ${ }^{3}$ inserido em seu país. Febvre afirma que Lutero sentia e pensava como um alemão, como um ser marcado por profundo idealismo e introspecção.

Por outro lado, essa relação entre a iniciativa pessoal e a necessidade social torna-se mais evidente no argumento de Febvre quando o autor observa que as motivações do jovem religioso, suas formulações advindas de profundo espiritualismo, seriam transformadas em fermento e discurso para o desejo de mudança da burguesia alemã, que já não se relacionava bem com a Igreja e com a fragmentação dos territórios germânicos. Essa transformação do impulso individual em resposta a uma necessidade social é descrita por Febvre nos seguintes termos: "A voz de uma Alemanha inquieta, surdamente palpitante de paixões mal contidas, que espera apenas um sinal, um homem, para revelar em público seus secretos anseios" (FEBVRE 2012, p. 116). Já nas últimas linhas de seu texto, Febvre faz uma síntese interessante dessa relação entre o indivíduo e o coletivo:

[...] Lutero e os homens de seu tempo, o grupo influenciado pelo indivíduo, o pensamento individual reduzido pelo pensamento coletivo. Um compromisso capenga e medíocre, como todo compromisso, viável, porque não era obra de um teórico legislando no abstrato: antes, a obra da experiência, de uma experiência a um só tempo feliz e cruel (FEBVRE 2012, p. 306).

Em tempos de discussões calorosas na cena cultural brasileira sobre o escopo e os limites das biografias, sobre o que seria permitido ou não ao biógrafo

${ }^{3}$ Conceito utilizado por Lucien Febvre nesta obra. 
fazer, o trabalho de Lucien Febvre sobre Martinho Lutero é particularmente interessante. Alguns críticos, ainda hoje, ressaltam que a obra não é uma mera biografia narrativa, pois o texto é amparado em crítica historiográfica e minuciosa análise de fontes (WOOLEY 2013). Esse raciocínio é particularmente interessante porque denotaria uma característica contrária à própria biografia. Não poderia, então, uma biografia narrativa ser também amparada em crítica historiográfica e minuciosa análise de fontes? Não nos parecem poucos os exemplos em que isso se constata. Que o próprio Lucien Febvre tenha querido afastar de sua obra o epíteto de biografia, é algo de que não resta dúvida. Mas o fato de o autor enunciar o que sua obra não é faz com que ela deixe de ser, faz com que os leitores não possam lê-la nessa direção? Todos os estudos sobre recepção, desde Jauss, não teriam demonstrado que enunciação e recepção não são especulares?

Se olharmos para os projetos intelectuais e institucionais de Lucien Febvre em 1928, não é difícil compreender por que lhe importa desvincular sua obra da perspectiva biográfica. Mas precisaria o leitor contemporâneo, embebido de todas as transformações que o gênero biográfico vivenciou na historiografia, sobretudo após os anos 1980, prender-se ao rótulo de Febvre (SCHIMIDT 2003; PRIORE 2009)? Sua obra não ganharia, para a nossa cena historiográfica, novas possibilidades, não se enriqueceria e abriria caminhos para novas discussões se a tratássemos exatamente assim, como uma biografia?

É interessante observar também que, como não poderia deixar de ser, a apresentação da obra em apreço nas resenhas da edição brasileira é acompanhada de uma apresentação de Febvre. Na resenha de Leonildo Silveira Campos, o Febvre dos anos 1920 é definido como um historiador "descontente com a maneira tradicional de se fazer história, quase sempre numa perspectiva política, desprezando-se as contribuições das demais ciências humanas". Leonildo Campos não está isolado em sua enunciação; ao contrário, está ancorado em vasta bibliografia que ainda hoje apresenta Febvre em tais termos. Trata-se de uma apresentação muito própria do autorretrato que Febvre constrói para si, especialmente ao longo dos anos 1940 e 1950, e que em ampla medida foi reproduzido, mas que não se mostra justo com a historiografia dos anos 1920. Diversos estudos têm demonstrado a vitalidade e a diversidade historiográfica desse período, seja na França, seja em outros países, assim como o diálogo efetivo com as ciências sociais ainda em formação.

Como Leonildo Campos assinala oportunamente, Febvre, ao escrever sobre Lutero, precisa afastar polêmicas, lendas, camadas de mitos e interpretações. Guardadas as devidas proporções, para falar de Febvre, precisamos usar os mesmos procedimentos, afastando camadas de mitos e polêmicas. Seguindo essa hipótese, este texto sobre Lutero torna-se para nós ainda mais relevante do ponto de vista da pesquisa em história da historiografia na medida em que aponta para a necessidade de se voltar para o estudo de autores que por vezes nos parecem já desgastados. Há muitos estudos que se dedicam a reafirmar o papel de Febvre como membro de uma grande escola, estudos que muitas vezes são revestidos de um caráter quase oficial. Parece-nos, no entanto, que 
ainda há muito a dizer a respeito de sua produção individual, de suas relações com historiadores contemporâneos, sem usar uma lente preestabelecida, sem apoiar-se nas categorias pré-definidas por esse "movimento dos Annales". Nesse sentido, a publicação desta biografia sobre Lutero parece-nos ser um passo importante em direção a novos caminhos para se estudar o historiador Lucien Febvre.

\section{Referências bibliográficas}

BERR, Henri. Luther et son milieux. A propos du Martin Luther de Lucien Febvre. Revue de Synthèse Historique, n. 22, p. 5-19, 1929.

CAMPOS, Leonildo Silveira. Estudo de Lucien Febvre retrata Lutero à luz do contexto social. Folha de São Paulo, 1 set. 2012. Ilustrada, p. E6.

CERTEAU, Michel de. A escrita da história. $2^{a}$ ed. Rio de Janeiro: Forense Universitária, 2008.

FEBVRE, Lucien. Martin Lutero: un destino. México: Fondo de Cultura Económica, 1998.

. Martinho Lutero: um destino. São Paulo: Três Estrelas, 2012.

HAUSER, Henri. Martin Luther: un destin. Revue Critique d'Historie et de Littérature, n.11, p. 499-502, 1928.

PIKETTY, Guilhaume. La biographie comme genre historique? Étude de cas. Vingtième Siècle: revue d'histoire, n. 63, p. 119-126, 1999.

PRIORE, Mary. Biografia: quando o indivíduo encontra a história. Topoi, v. 10, n. 19, p. 7-16, 2009.

SCHIMIDT, Benito Bisso. Biografia e regimes e historicidade. Métis: história e cultura, v. 2, n. 3, p. 57-72, 2003.

WOOLEY, Patrícia. Um destino. Revista de História, 8 jan. 2013. Disponível em: http://www.revistadehistoria.com.br/secao/livros/um-destino. Acesso em: 28 jan. 2014. 